\title{
Results of Distal Tibia Extra-Articular Type I \& Type II Open Fractures Treated with Primary Ilizarov External Fixator - A Prospective Observational Study
}

\author{
Debanga Sarma Barua ${ }^{1}$, Monoranjan How Bora² ${ }^{2}$ Manas Jyoti Das ${ }^{3}$, Sidhartha Bansal ${ }^{4}$ \\ ${ }^{1}$ Assistant Professor, Department of Orthopaedics, Assam Medical College, Dibrugarh, Assam, India. ${ }^{2}$ Postgraduate \\ Student, Department of Orthopaedics, Assam Medical College, Dibrugarh, Assam, India. ${ }^{3}$ Registrar, Department of \\ Orthopaedics, Gauhati Medical College, Guwahati, Assam, India. ${ }^{4}$ Postgraduate Student, Department of Orthopaedics, \\ Assam Medical College, Dibrugarh, Assam, India.
}

\section{ABSTRACT}

\section{BACKGROUND}

Distal tibia fractures are a common consequence of road traffic accidents or sport injuries and are considered to be difficult to treat surgically as tibia lies subcutaneously, has precarious blood supply, has high risk of infection, risk of skin necrosis after internal fixation and may also go for malunion and non-union. The prime advantage with Ilizarov technique is that with this technique one can treat the patients with an immediate single stage procedure irrespective of soft tissue status.

\section{METHODS}

19 patients $(\mathrm{M}=15, \mathrm{~F}=4)$ in 18-65 years age group with isolated distal tibia extraarticular fractures open type I \& II who were undergoing treatment with circular external fixator (Ilizarov technique) were included in the study conducted from $1^{\text {st }}$ July 2017 to $31^{\text {st }}$ May 2018. Depending on the type of fractures, 3 or 4 rings with or without foot frame were used. Full weight bearing was allowed in all cases. Operative time (In minutes), intraoperative blood loss by mopping method, clinico-radiological union, intra-operative complications, post-operative complications, and ankle range of motion were assessed. American Orthopaedic Foot and Ankle Society (AOFAS) score was taken to assess functional outcome. Average follow up period was 11 months (Range 6-16 months).

\section{RESULTS}

According to AO classification, A1 fractures were five, A2 fractures were ten and four had A3 fractures. 11 had Gustilo type I and 8 had type II injuries. Mean hospital stay was 9 days (range 5-14 days). Mean ankle dorsiflexion was $18^{0}$ and plantarflexion was $30^{\circ}$. Pin tract infection was seen in $5(26.31 \%)$ of our cases which were not deep, and they were treated successfully after giving oral antibiotics and local pin tract care. All patients had satisfactory AOFAS score. Only one patient had non-union which was treated with corticotomy and distraction osteogenesis.

\section{CONCLUSIONS}

We recommend using Ilizarov circular ring fixator application in such type of fractures as it has got minimum complication rate and most importantly it can be done as single stage procedure irrespective of soft tissue status. Immediate postoperative ambulation and weight bearing can be given via this device.

\section{KEY WORDS}

Distal Tibia, Extraarticular, Open Type I \& II, Ilizarov External Fixator
Corresponding Author: Dr. Monoranjan How Bora, Postgraduate Student, Department of Orthopaedics, Assam Medical College, Dibrugarh, Assam, India.

E-mail: howboramonoranjan@gmail.com

\section{DOI: $10.14260 / \mathrm{jemds} / 2019 / 620$}

Financial or Other Competing Interests: None.

How to Cite This Article: Barua DS, Bora MH, Das MJ, et al. Results of distal tibia extra- articular type I \& type II open fractures treated with primary ilizarov external fixator- a prospective observational study. Evolution Med. Dent. Sci. 2019;8(37):2856-2860, DOI: $10.14260 /$ jemds/2019/620

Submission 10-05-2019, Peer Review 18-08-2019, Acceptance 24-08-2019, Published 16-09-2019.

\section{(c) (i) $\ominus$}




\section{BACKGROUND}

Distal tibia fractures are a common consequence of road traffic accidents or sport injuries and account for approximately $37.8 \%$ of all tibial injuries.[1] These fractures may be either extra-articular or intra articular affecting the diaphyseal metaphyseal area of the bone, intra-articular fractures are known as pilon or plafond fractures. For orthopaedic surgeons these fractures are still challenging. ${ }^{[2]}$ Because of the elevated risk of complications which may result from the nature of the injury itself or secondary to surgery, these fractures are considered as severe injuries. Distal tibia extra-articular fractures are unique in that the bone is having precarious periosteal blood supply because it has got less muscle cover and is subcutaneous. These fractures lead to various complications like wound dehiscence, infection delayed bone healing and non-union. As a close method, intramedullary nail spares the periosteal blood supply and avoids extensive soft tissue dissection. However, intramedullary nail, increases the frequency of mal alignment in proximal and distal third fractures due to difficulty to control the fragment.

The goal of treatment in distal tibia extra-articular fractures are to achieve normal axial alignment, length and rotation and without infections and wound complications to regain a stable, mobile and painless joint. [3]

Regarding definitive treatment point of view these fractures are challenging for orthopaedic surgeons.[4] Assessment of anticipating risks for post-operative complications are difficult because of the variations in the clinical findings. Sometimes in extra-articular fractures also, injury can be more serious as compared to initial expectation. According to literature, uni-planar and bi-planar external fixator can also be applied in treatment of closed tibial shaft fractures. However, they do not allow weight bearing, can cause problems of pin loosening, infection and at times can cause insufficient mechanical stability. Traditional open reduction and internal plate fixation (ORIF) achieves an acceptable reduction and rigid fixation, but requires extensive soft tissue dissection and periosteal stripping, and these factors increase the rates of complications, including infection, delayed union and non-unions.[5,6]

The Ilizarov external fixator is best indicated for tibial fractures, because of allowing early weight bearing.[7] Ilizarov method has proved that to be effective in the treatment of post-traumatic non-union of the tibia where the other types of treatment had failed.[8] Ilizarov external fixator allows correction of three dimensional deformities rotation, translation, angulation and correction of shortening, widening, lengthening and soft tissue defects. ${ }^{[9]}$ When using the Ilizarov technique some tethering of muscles and tendons is inevitable and this would theoretically affect range of motion (ROM) of knee and ankle.[10] Pin site infections form the bulk of complications associated with care of pin sites and aggressive management of superficial infections is essential to prevent deep infection. Insufficient pin care has been associated with higher incidence of pin-tract complications.[11]

In case of fixation with locking plate by MIPO technique it needs two stage procedures in most of the cases because of the soft tissue conditions. The prime advantage with Ilizarov technique is that with this technique one can treat the patients with an immediate single stage procedure, ${ }^{[12]}$ irrespective of soft tissue status, with minimal soft-tissue exposure and less invasive. With this circular ring fixator, adjustment can be done if required and compression/distraction both can also be done if there is delayed bone healing or non-union after surgery. Another advantage is that with Ilizarov external fixator application, immediate postoperative weight bearing[13] can be allowed because with $1.8 \mathrm{~mm}$ trans-osseous wire fixation, apparatus is stable enough.

At department of Orthopaedics, Assam Medical College we treated distal tibia extra-articular open type I \& II fractures with Ilizarov external fixator from $1^{\text {st }}$ July 2017 to $31^{\text {st }}$ May 2018. The aim of this study was to assess the functional and radiological outcome with the Ilizarov circular ring fixator application.

\section{METHODS}

The study was carried out in the Department of Orthopaedics, Assam Medical College \& Hospital, Dibrugarh from $1^{\text {st }}$ July 2017 to $31^{\text {st }}$ May 2018 comprising 19 skeletally matured patients with distal tibia extra articular open type I \& II fractures attending Orthopaedic OPD and Emergency were selected in the study. Before participation in our study we obtained written and informed consent from all the cases. On the basis of AO \& Gustilo Anderson classification, fractures were categorized. Cefoperazone and Sulbactam injection was given immediately before operation.

\section{Surgical Technique [14]}

The cases were operated in traction table without application of tourniquet. Before operative procedure, preassembled rings (3 full rings and 4 threaded rods between two rings) were sterilized. After skin painting and draping, the ring was introduced into the leg then the first transverse wire was passed most distal to the fracture site near the ankle joint. Another wire was inserted transversely proximal to the fracture towards the knee joint. Alignment of fracture site was adjusted under c-arm guidance by passing other transverse wires near the fracture site. Other wire was passed at least 45 degree to first wire. $1.8 \mathrm{~mm}$ plain wires and cases where alignment could not be achieved with plain wires, olive and drop wires were used to achieve reduction. All the wires were fixed to the ring on one side and tensioned on other side according to fracture configuration. Only olive tip wires were not fixed to ring before tensioning. After getting reduction in all planes, rings proximal and distal to fracture site were fastened with threaded rods. In case the fracture is still unstable after reduction we fix the half ring to the main frame for added stability. In all cases 160 rings were used. For each ring, minimum of 2 wires were used. While inserting the wires they were first gently pushed up to the bone through skin and then drilled with power drill. After coming out through other cortex, they were hammered gently to get out to other side. Muscles were at their maximum length while inserting the pins and all the wires were passed through safe zones. The wire sites were dressed with normal saline soaked gauzes. 


\section{Postoperative Protocol}

Radiograph with standard anteroposterior and lateral view of the involved leg was taken immediate postoperatively, at 1 month, 3 months and 6 months. Immediate postoperative physiotherapy was started in every case to prevent knee and ankle stiffness, sandal with elastic attached with ring were also given to prevent equinus deformity, weight bearing was also allowed immediate post-operatively. Union of the fractures were said when antero posterior and lateral radiographs showed obliteration of fracture line with bridging trabeculae. The patients were followed at 1 month, 3 months and 6 months. American Orthopaedic Foot and Ankle Society Score (AOFAS),[15] and degree of ankle dorsiflexion and plantar flexion of injured limb were compared with the uninjured one at 3 months and 6 months.

\section{Statistical Analysis}

Frequencies and percentage of quantitative variables were presented with Mean \pm SD (Standard deviation). The data collected was tabulated in Microsoft Excel Worksheet and computer-based analysis was performed using the Statistical product and service solutions (SPSS) 22.0 software (SPSS, Chicago, Illinois, USA). The categorical variables were summarized as proportions and percentages.

\section{RESULTS}

Between $1^{\text {st }}$ July 2017 and 31 ${ }^{\text {st }}$ May 2018, patients admitted to the department of Orthopaedics, Assam Medical College and who fulfilled the inclusion criteria were taken in our study. Average age was 40 years (Range 18-65). There were 15 $(78.95 \%)$ males and $4(21.05 \%)$ females in the study with $60 \%$ having right tibia involvement. On the basis of $\mathrm{AO}$ classification, fractures were categorized; the most common type was 43A2 with $10(52.63 \%)$ patients whereas $5(26.32 \%)$ were in Type $43 \mathrm{~A} 1$ and 4 (21.05\%) in Type 43A3.11 (57.89\%) patients were included in Gustilo \& Anderson open type I and $8(42.11 \%)$ were in type II.

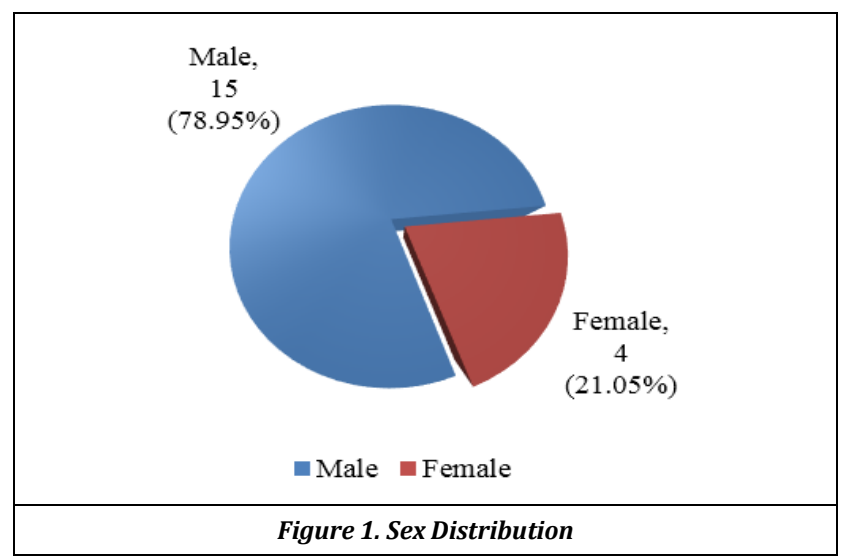

The most common mode of injury was road traffic accident (RTA) seen in 60\% patients followed by falls, sport injury (e.g. football). All surgeries were done within 1-7 days of injury. The average operating time was 110 minutes (Range 90-130 minutes). Average time of union was 15 weeks (Range 12-24 weeks). Ilizarov fixator was removed after average period of
15 weeks (Range 12-24 weeks). Non-union was seen in only 1 of our patients which was treated with corticotomy and distraction osteogenesis and union was achieved. Pin tract infections were seen in 5 of our cases which were superficial and treated by application of local and systemic antibiotics. Mean AOFAS score was 88. All the patients had full knee function.
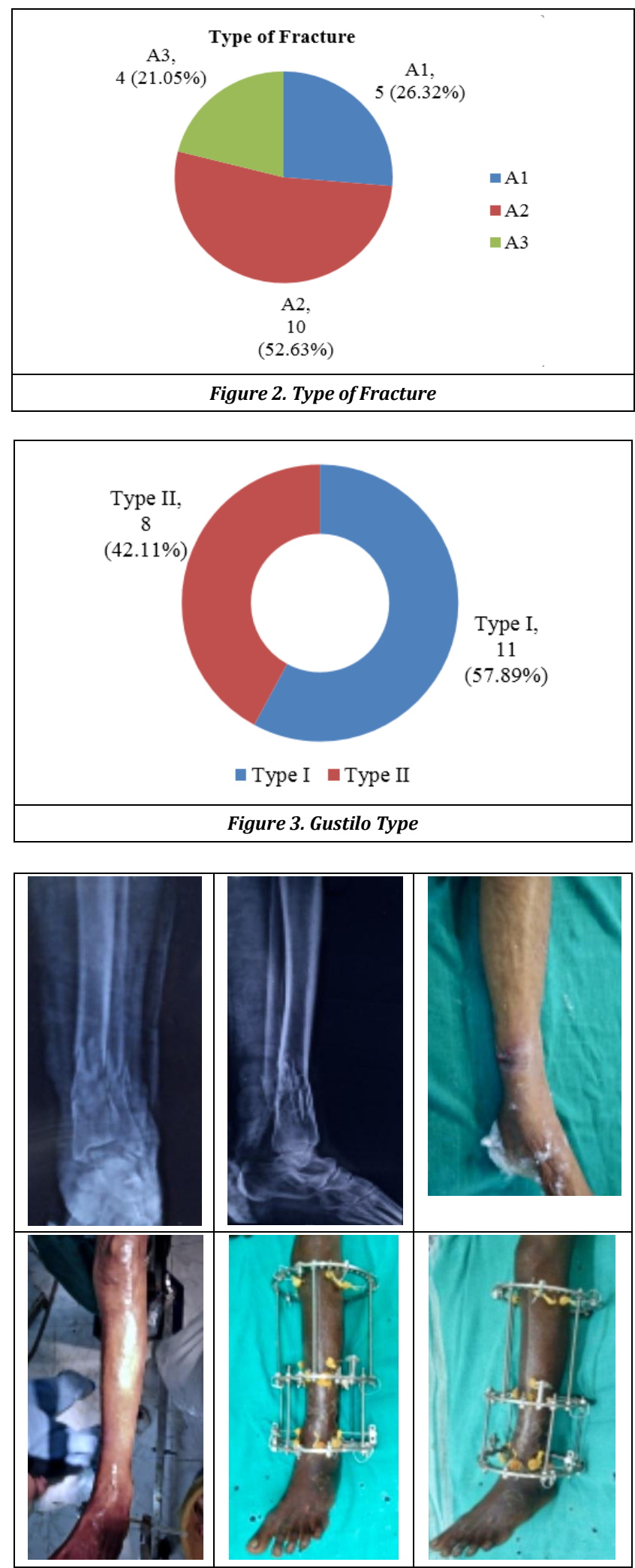

A 50-Year-Old Female Patient Presented with RTA- Open Type II Fractures-Preoperative $X$-Ray and Immediate Postoperative Photo 

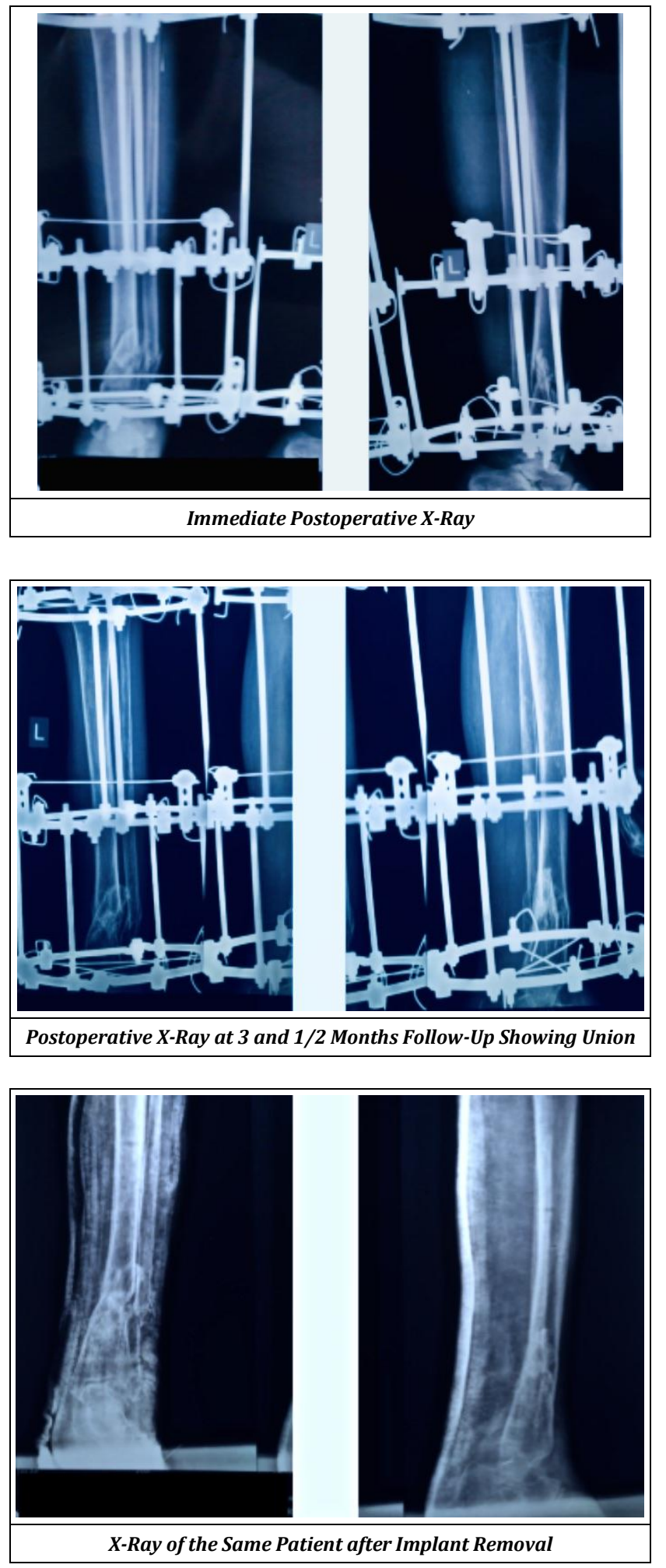

\begin{tabular}{|c|c|}
\hline Average hospital stay & 9 days (5-14 days) \\
\hline Average blood loss & $150.53 \pm 8.64 \mathrm{ml}$ \\
\hline Average operating time & 110 minutes $(90-130$ minutes $)$ \\
\hline Average union time & 15 weeks $(12-24$ weeks) \\
\hline Implant removal & 15 weeks $(12-24$ weeks $)$ \\
\hline Non-union & $1(5.26 \%)$ case \\
\hline Pin site infection & $5(26.32 \%)$ cases \\
\hline AOFAS score & $88.42 \pm 6.47$ \\
\hline \multicolumn{2}{|c|}{ Table 1. Showing Final Outcome } \\
\hline
\end{tabular}

\section{DISCUSSION}

Extra articular distal tibia open fractures which are presented to orthopedician, have a wide range of treatment modalities from closed reduction, external fixation to internal fixation. The objectives in the treatment of these fractures are rapid and ideal healing, minimisation of loss of function and prevention of any deformity. Shortening, angulation, non-union, infection, loss of ankle range of motion (ROM) and delayed weight bearing have been reported as the most common complications of internal fixation. Distal tibia has less vascular and soft tissue support than any other part of the tibia.[16] Infection has been a more common complication, particularly in open tibia fractures treated by plate fixation. It is known that open reduction and plate fixation of the traumatised extremity will further increase soft tissue damage and risk of compartment syndrome.[17] Because of the widening of medullary canal in the metaphysis in case of distal tibia extraarticular fractures, application of intramedullary nailing is challenging, regarding the biomechanical stability[18] it also raises concern.

Regarding treatment options available for distal tibia extra-articular fractures, none of them can accurately fulfil requirements of fracture characteristics. Intramedullary nail which is designed for diaphyseal fractures cannot provide same biomechanical stability at distal fractures, ${ }^{[19,20]}$ due to presence of circular cross-sectional area with thinner cortex. ORIF with conventional plate is not an ideal treatment option because bone is a subcutaneous with precarious blood supply. ORIF with conventional plating has non-union rate of 8.3$35 \% .[21-24]$

Pin site infection is common problem with Ilizarov ring fixator application. The incidence of pin site infections reported in the literature varies from $4.5 \%$ to $71 \%$ and pin tract infection varies from $10 \%$ to $50 \%$. In our study $26.31 \%$ of the pin sites became infected, which were superficial and treated successfully by local and systemic antibiotics.

In our study, most common cause for these fractures was RTA followed by fall and sports injury. Our results were comparable to other studies by Kumar et al.[25] Ram et al.[26] which also showed that RTA is the most common mode of injury as modernization and industrialization have intruded our lives. In our study, the operating time ranged from 90 to 130 minutes this was comparable to study done by Ramos et al. In our study we started immediate postoperative weight bearing which was supported by other study done by Ramos et al.

Functional outcome according to AOFAS score was 88 in our study which was similar to other studies by Ramos et al., Collinge et al.

\section{CONCLUSIONS}

We recommend this versatile technique for the treatment of distal tibia extra-articular fractures open type I \&II, where it is possible to get a satisfactory clino-radiological outcome. With Ilizarov circular ring fixator application, we can treat such type of fractures as a single stage procedure regardless of soft tissue status and immediate post-operative weight bearing can be allowed. We acknowledge that with more number of cases with comparable group in this study, the results and observations would have been more accurate. Number of the patients, duration, and follow up of our study was shorter due to limited time period. We think more time is required for proper assessment of functional and clinical outcome. 


\section{ACKNOWLEDGEMENT}

We are thankful to, the Department of Orthopaedics, Assam Medical College, and the patients who participated in this study.

\section{REFERENCES}

[1] Mahmood A, Kumar G. Review of the treatment of distal tibia metaphyseal fractures: plating vs intra medullary nailing: a systemic review of recent evidence. Foot Ankle Surg 2014;20(2):151.

[2] Heim V. Die pilon tibial fracture. Berlin: Springer 1990.

[3] Rockwood and Green's Fracture in adults. $6^{\text {th }}$ edn. Philadelphia: Lippincott Williams \& Wilkins Publisher 2006.

[4] Joveniaux P, Ohl X, Harisboure A, et al. Distal tibia fractures: management and complications of 101 cases. Int Orthop 2010;34(4):583-8.

[5] Im GI, Tae SK. Distal metaphyseal fractures of tibia: a prospective randomized trial of closed reduction and intramedullary nail versus open reduction and plate and screws fixation. J Trauma 2005;59(5):1219-23.

[6] Janssen KW, Biert J, Van Kampen A. Treatment of distal tibial fractures: plate versus nail: a retrospective outcome analysis of matched pairs of patients. Int Orthop 2007;31(5):709-14.

[7] Pavolini B, Maritato M, Turelli L, et al. The Ilizarov fixator in trauma: a 10-year experience. J Ortop Sci 2000;5(2):108-13.

[8] Tranquilly LP, Merolli A, Perrone V, et al. The effectiveness of the circular fixator in the treatment of post-traumatic tibia of the non-union. Chir Organi Mov 2000;85(3):235-42.

[9] Jauering PR. Oranizing and implementing an Ilizarov programme. Orthop Nurse 1990:9(5):47-55.

[10] Sahtarker H, Gilson SC, Stolero J, et al. External fixator as an alternative treatment for tibial shaft fractures in adolescents. Ortho Proc 2002;84-B(Suppl 3).

[11] May JD, Paavana T, McGregor-Riley J, et al. Closed tibial shaft fractures treated with the Ilizarov method: a ten year case series. Injury 2017;48(7):1613-5.

[12] Ilizarov GA. Collected scientific works of the Kurgan Regional Scientific Medical Society. In: Ilizarov GA, edr. A new principle of osteosynthesis using crossing wires and rings. Kurgan: Union of Soviet Socialists Republic 1954: p. 145-60.
[13] Ylmaz E, Belhan 0, Karakurt L, et al. Mechanical performance of hybrid Ilizarov external fixator in comparison with the Ilizarov circular external fixator. Clin Biomech (Bristol, Avon) 2003;18(6):518-22.

[14] Rhinelander FW. The normal microcirculation of diaphyseal cortex and its response to fracture. J Bone Joint Surg Am 1968;50(4):784-800.

[15] Kitaoka HB, Alexander IJ, Adelaar RS, et al. Clinical rating system for the ankle-hindfoot, midfoot, hallux and lesser toes. Foot and Ankle Int 1994;15(7):349-53.

[16] Muller ME. The comprehensive classification of fractures of the long bones. In: Muller ME, Allgower M, Schiender R, et al. eds. Manual of Internal fixation. $3^{\text {rd }}$ edn. New York: Springer-Verlag 1991.

[17] Mosheiff R, Safron O, Segal D, et al. The undreamed tibial nail in the treatment of distal metaphyseal fractures. Injury 1999;30(2):83-90.

[18] Bridgeman SA, Baird K. Audit of closed tibial fractures: what is a satisfactory outcome? Injury 1993;24(2):859.

[19] Kneifel T, Buckley R. A comparison of one versus two distal locking screws in tibial fractures treated with unreamed tibial nails: a prospective randomized clinical trial. Injury 1996;27(4):271-3.

[20] Trafton PG. Tibial shaft fractures. In: Browner DB, Jupiter JB, Levine AN, et al. eds. Skeletal trauma. $4^{\text {th }}$ edn. Philadelphia: Saunders Elsevier 2009: p. 2319-452.

[21] Redfern DJ, Syed SU, Davies SJM. Fractures of the distal tibia: minimally invasive plate osteosynthesis. Injury 2004;35(6):615-20.

[22] Apivatthakakul T, Phornphutkul C, Patumasutra S. Idea and innovation: simple minimally invasive plate osteosynthesis (MIPO) instruments. Injury Extra 2009,40(2):39-44.

[23] Vallier HA, Le TT, Bedi A. Radiographic and clinical comparisons of distal tibia shaft fractures (4 to $11 \mathrm{~cm}$ proximal to the plafond): plating versus intramedullary nailing. J Orthop Trauma 2008;22(5):307-11.

[24] Yang SW, Tzeng HM, Chou YJ, et al. Treatment of distal tibial metaphyseal fractures: plating versus shortened intramedullary nailing. Injury 2006;37(6):531-5.

[25] Kumar D, Ram GG, Vijayaraghavan PV. Minimally invasive plate versus intramedullary interlocking nailing in distal third tibia fractures. IOSR J Dent Med Sci 2014;13:15-7.

[26] Ram GG, Kumar D, Phagal VV. Surgical dilemma's in treating distal third leg fractures. Int Surg J 2014;1:13 6. 